\title{
Analysis of the Restrictive Elements of China's Textile Industry in Upgrading Based on "Value Chain"
}

\author{
Tong Yang, Meilin He \& Aixiang Zhang \\ School of Management, Xi'an Polytechnic University \\ Xi' an 710048 , China \\ E-mail: yangtong1268@163.com
}

\begin{abstract}
Our country's textile industry is in the producing and processing field in the global value chain, so textiles' added value is low and profit margins is narrow. Developed countries take up fields of high-grade fabrics production and advanced textile machinery manufacture. Because textile fabrics, textile machinery and equipment of China's textile industry fall behind developed countries, product quality and product variety can not yet fully meet the market demand, and can not compete with developed countries. In order to quicken the upgrade pace of textile industry, this paper brings forward some measures on the Chinese textile fabrics and textile machinery deficiencies.
\end{abstract}

Keywords: Upgrading, Value chain, Restrictive elements, Textile industry

With the rapid development of technology and the deepening of Globalization, there are some difficulties in the development of textile industry. Faced with internal and external pressures which raw material prices and labor costs are rising, RMB devaluates, the State Environmental Protection is stepping up and a variety of technical barriers have been introduced, China's Textile Industry should develop to the "strategic section" of global value chain on the basis of the theory of Value Chain-R\&D and manufacture of advanced textile machinery and development and production of high-grade fabrics to promote the Textile Industry to upgrade. Due to this link is crucial and strategic in the Value Chain of Textile Industry, having very high technological content and valued-added (Jiang, 2008).

\section{Theoretical Basis of China's Textile Industry to Upgrade}

The concept of "Value chain" was advanced by Michael Porter, a professor of the Harvard Business School, in a book named "competitive advantage" in 1985 . He considered that every corporation was a collective body of various activities in the process of design, production, sales, sending and supporting products, and all of these activities can be denoted by a value chain (Porter, 2005). The basic view of "The Theory of Value Chain" is that not every link can create value in a many "value activities" of enterprise. The value created by enterprise, in fact, is from specific value activities of enterprise's value chain. Operating activities creating the real value is the "strategy session" in the Value Chain. The advantage of business in the competition, especially to maintain the advantage in the long term, is the advantage of certain link (Zhou, 2009).

\section{China's Textile Industry be in Which Links in the Global Value Chain}

According to the hierarchical classification of the Textile Industry's Chain, using "Smile Curve" shows China's textile industry is in what position in the industrial chain, so as to further explore the developmental focus-R\&D of unmarked fabrics and manufacture of advanced machinery, to grasp strategic links of Value Chain, and to promote the textile industry to upgrade.

\subsection{Level of the Textile Industry Value Chain}

The Textile Industry's value chain is divided into five levels: United States, Western Europe and Japan are at the first level which is the most high-end value chain. In this level, products contain high technology and high added value. They hold market channels and the most sophisticated technology, and occupy the two ends of chain. Korea, Hong Kong and Taiwan are at the second level. These nations are newly industrialized countries. They control the service mechanism, adjust the industrial structure, focus on the development of raw materials, and master the front-end chain. China is at the third level with a huge industrial base, having outstand advantages in manufacturing areas and a small proportion of high value-added products. Meanwhile, private label share has a bigger gap than international standards. India, Pakistan, Indonesia are at the fourth level. These nations aim at having relatively low labor costs and parts of conditions which accept the transfer of textile industry (Jiang, etc., 
2008).

\subsection{Overview of Smile Curve of Textile Industry}

In 1990, Shi Zhengrong, a chairman of Taiwan's Acer Group, put forward the concept of "Smile Curve". Using a Parabola opening up describes all aspects of Added Value in manufacturing process of personal computer (Chen, 2006)."Smile Curve" phenomenon exists not only in the computer industry, but also in other industries. So "smile curve" theory is widely used in various fields. "Smile Curve" applied to the textile industry is shown in the Figure 1.At the left of the curve, development and production of high-grade fabrics and research and manufacture of advanced textile machinery are the highest technological content and the highest value-added sectors in the entire industry chain. That is, it is a key link called "strategic sector" in the Value Chain. At the right of the curve, with the constant improvement of sales network and operations of brand innovation, value-added of products has also increased. The middle part of the curve is standardized processing and manufacturing sector which products are low technology and low value-added.

\subsection{The Link of China's Textile Industry in the Value Chain}

By describing layers of Textile Industry's industrial chain and characteristics of textile industry's "Smiling Curve", it is easy to find that these nations lying in the first and second level control unmarked and upfront technology. At the same time, terminal perfect services, marketing channel and famous brands of the World are controlled by other countries. China's Textile Industry lies in the link of labor-intensive process and production, so can only earn slender margin in processing area where profit margins is getting smaller. However, the production of high-grade fabrics and manufacture of advanced textile machinery are the highest technological content and high added value sectors in the Textile Industry's chain. This shows that contribution rate of science and technology of China's textile industry is very low. At present, the contribution rate to economic growth accounted for about $20 \%$, which is lower than the national average $(28.7 \%)$ and much lower than international developed country level( $60 \%-80 \%)(\mathrm{Li}$, etc. 2006$)$.

\section{Limiting Factors Analysis of China's Textile Industry Upgrading}

China's Textile Industry produces the largest scale Textiles of the World. However, the strength of the development and production of high-grade fabrics and advanced textile machinery is not enough and there is still a larger gap than the international advanced level.

\subsection{Insufficiency in Developmental and Manufacturing Strength of High-grade Fabrics}

The production of high-grade fabrics is a key and strategic link in which technological content is high. It is key factor for upgrading of textile industry.

\section{(1) High-grade Fabrics Mainly Relying on Imports}

China is a big consumptive country of textile fabric and is also a major importer. High-grade fabrics mainly rely on import. According to customs statistics, China's total imports of fabrics are 15.49 billion dollars, up 1.42\%, which accounted for $90.59 \%$ of textiles and clothing's total imports (17.099 billion dollars) in 2005. China's total imports of fabrics are 16.354 billion dollars, up 5.58\%, which accounted for $90.60 \%$ of textiles and clothing's total imports (18.051 billion dollars) in 2006. The last two years, high-grade textile fabrics of $75 \%$ mainly relied on imports. But now, imports of high-grade fabrics is no less than 50\%.At present, Statistical Data shows that self-sufficiency rate of our fabrics is about $40 \%$ and clothing enterprises need 6 billion dollars to import fabrics ever years(China Dyeing and Printing Networ).

At present, fabrics of $60 \%$ in medium and high grade clothing fabrics exports of China relied on import. In 2006, imports of fabrics amounted to 8.95 billion dollars, meanwhile the average unit price of imports fabrics are generally higher than export fabrics. While, the average unit price of China's cotton, chemical fiber and wool imports were higher 0.34 dollar per meter, 0.38 dollar per meter and 2.17 dollars per meter than exports (Tian, 2008).

\section{(2) Lack of New Technologies of Product Development and Design}

In quality and appearance, domestic fabrics mishandle the trend and have few flower shapes, old colors and few new fabric blends. Chemical fiber fabrics of high texture and ultra-real simulation and novel multi-component natural fiber blend fabrics are scarce. At the same time, comparable to import fabrics, domestic fabrics have high shrinkage, low color fastness, poor shape and stability, and are easy to shrink and not natural and unmarked. There are poor effects of finishing, inconsistent width, unstable quality of cloth edge, multi-wood ears, severe hot color, poor color and brightness and so on. There are some difficulties in producing high-quality garment, and can not meet demands of high-end clients and high-grade consumption. 
In addition, domestic fabrics are still can not fully meet the requirements of health care. Health care performance of fabrics is one of important properties of Apparel Fabrics, including comfort and security of the clothing. With the improvement of people's living standards, hygienic performances of fabrics are more concerned. So health will become the first choice of Apparel Fabrics (Qu, 2006).

\section{(3) Lack of Innovation and Fashion of Domestic Fabric}

By seeing the overall innovation performance of popular color and trend of domestic fabric, it is lack of original innovation and designation, especially is lack of design capabilities of overall integration. The shortage of capacity to develop technology mainly represents in the older manufacturing technology and not rich finishing methods, which makes mechanism of fabrics and clothing performance capabilities slight blankness. Although some large producers are lack of R\&D of new technology and complement of software, the situation which using advanced equipments produce fabrics of middle-grade and middle-grade has not been fundamentally changed.

Furthermore, the mock phenomenon of fabric industry is entirely serious. The modification of equipment does not effective integrate with technology and product development. So, product advantages can not be formed, products of high value-added can not produced, and high-grade fabrics can not be effective supplied.

\subsection{Lake of Strength of Advanced Textile Machinery's Research Development and Manufacturing}

The manufacturing level of textile machinery is also an important indicator of the competitiveness of the textile industry of a country or region. The textile industry's development must be supported by advanced textile machinery. The upgrade of China's textile industry is related to the upgrade of the textile equipment industry, which is the necessary foundation and prerequisite (Zhu, 2009).

Firstly, Circle of "Introduction - Backward - Reintroduction". Some say China's textile industry has entered into a strange cycle of purchase imported equipment: entrepreneurs raise much capital to import foreign textile machineries and equipments which product textile, but only making a small profit. A few years later, the updated foreign textile machinery has entered into the Chinese market too. In order to maintain their advantage in the industry, entrepreneurs have to invest the accumulation of capital to the new textile machinery. So the cycles, most of the meager profits are used to buy another update device. Ultimately, it will lead to a vicious circle of "introduction - backward - reintroduction" (Guo, 2006).

Secondly, lower degree of specialization. Textile Industry is a batch and variety and small amount industry. Currently, the size of the majority of foreign textile machinery enterprises is hundreds of people. They focus on one process and have a strong professional. Many companies specialize on one product and become famous brand of the World in this area. In contrast, the production scale of domestic textile machinery is large and comprehensive or small and comprehensive, low degree of specialization, lack of products with special advantages and large numbers of small and medium domestic enterprises go the road of multi-industry, which make enterprises have no features and advantages.

\section{Conclusions}

Overall, for all great variety of goods of china's textile machinery, traditional machinery of fibers' processing plays a dominant role in textile machinery products. It needs to be improved from the following areas: reliability and stability; higher failure rate; integration of information and intelligence; automation, etc.

\section{References}

Chen Honglin. (2006). BenQ Recycling Itself by "Smile Curve". PC World, 11:191.

China Dyeing and Printing Network. Current Situation of Production and Import and Export of China's Textile Fabrics and Accessories. [Online] Available: http://www.cnprintingweb.com/MarketTrade.

Guo Yan. (2006). The Strategy study of China Textile Industry Development from OEM to OBM. Hunan: Huan University.

Jiang Hongfei, Xu Weilin \& Zhou Wei. (2008). Seven-inch of Industry Chain", Self-innovation and the Textile Industry Upgrading. Contemporary Economic Management, 30(7):49-52.

Jiang Zhu \& Guo Wei. (2008). Ways of Textile Industrial Upgrading in the Progress of Chinese New Type Industrialization. Journal of Textile Research, 29(7):117-121.

Li Chang, Wang Liping \& Ren Rongming. (2006). Analysis of Development History and Existing Problem of China's Textile Industry. Textiles of Jiangsu, (3): 1-2.

Porter (a), Chen Xiaoyue (translation). (2005). Competitive advantage. Beijing: China Press, 69-80. 
Qu Yibin. (2006). Development of Domestic Textile Fabric. Textile Technology, 6:56-58.

Tian Shufeng. (2008). Analysis of Current Situation and Countermeasures of Industry Chain in China. Silk of Liaoning, 3:1-3.

Zhou Xi. (2009). Overview of Value Chain Theory of Global. Economist, 2009, 6:33-34.

Zhu Zefei. (2009). Textile Upgrade can not be separated from Textile Machinery. Practice of Trade, 5: 18-19.

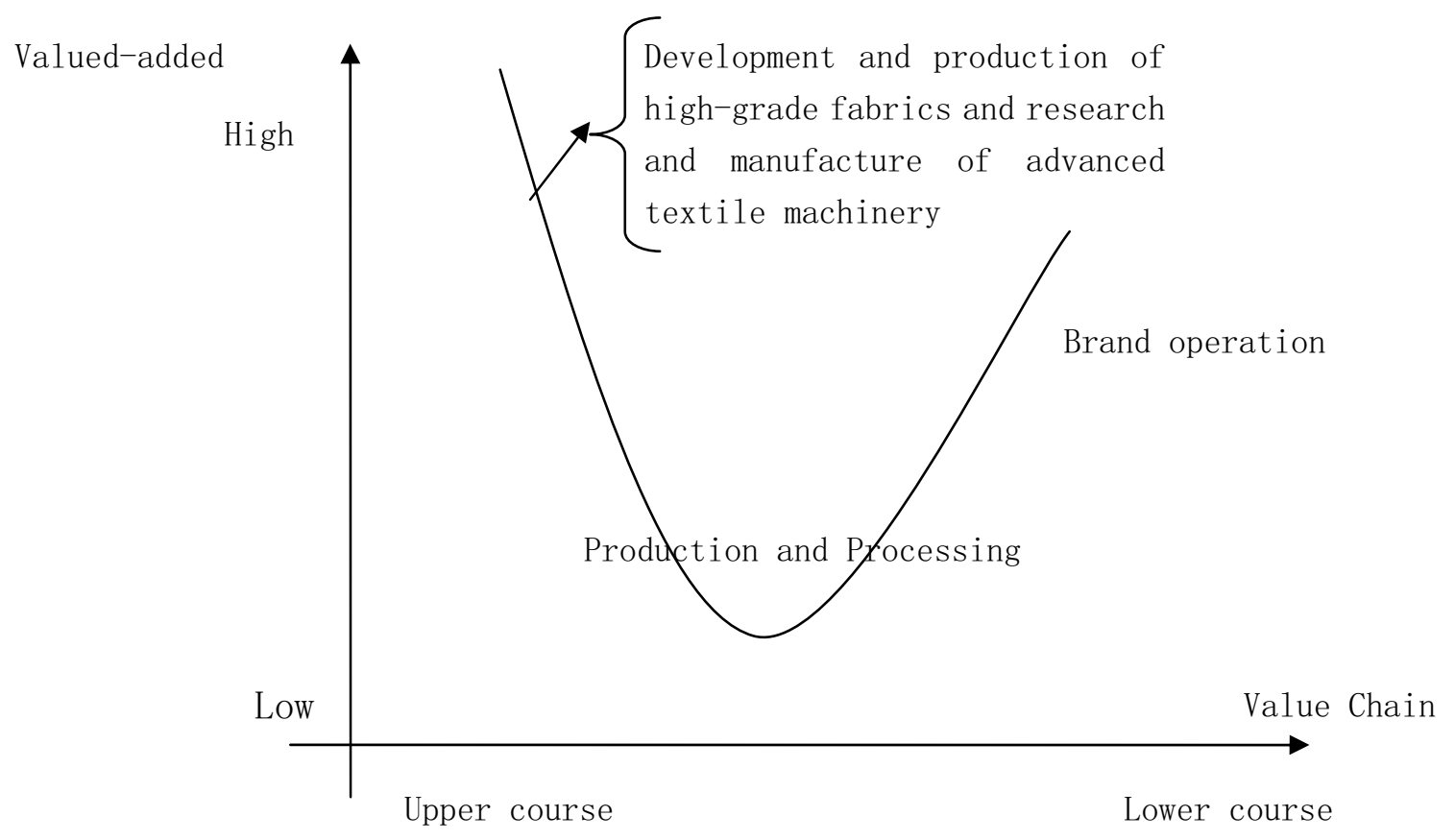

Figure 1. "Smile Curve" of Textile Industry 